\title{
SELF-PRESENTATION ON PERSONAL HOMEPAGES
}

\author{
Heidi Glatzmeier, Gerald Steinhardt \\ Vienna University of Technology, Austria
}

\begin{abstract}
This paper is based on a study that investigates the self-presentation on homepages on three levels. On the first level we explore the content that was used for presenting oneself on homepages and we examine if certain "dos and don'ts" have been established in the choice of content as well as in the way of presentation. The second level does a reconstruction of the significance of content for the given material within the author's scope of meaning. On the third level the study tries to find cultural explanations for the "selfrepresentation on personal homepages" phenomenon.
\end{abstract}

Key words: World Wide Web, Home pages, self-presentation.

\section{INTRODUCTION}

The economist and philosopher Georg Franck (1998) reflects on contemporary social life from a specific point of view, namely the perspective of a constant struggle for attention. Attention is no longer given freely to an individual but has to be gained by fighting for it.

Whenever people meet they present themselves to their peers. Their peers then create a profile of them based on how the person presents himself: The appearance of a person increasingly becomes more important than the person's being itself (see Haug, 1971). The more successful a person is when presenting himself, the better he can impress his peers.

A possible explanation for this feature of contemporary society may be the fading importance of societal institutions, which in the past regulated who was at what time entitled to what quantum of attention. The equal treatment and equal status of all members of society, an idea strived for since the Enlightenment and enforced today (at least on paper), promises - at least 
implicitly - everyone the chance of achieving anything they want (see Horkheimer \& Adorno, 1996). In late modernity this development led to the process of individualisation as described by Beck, which came along with the obligation for the individual to be successful in life (see Beck, 2001).

But success and social prestige can only be achieved by somebody who manages to draw attention to himself. Attention becomes a good that is in short supply and has to be fought for using self-presentation. Franck (1998) depicts this social phenomenon through the metaphor of a pub where everyone talks at the top of their voice and every single person has to shout to be heard by the others.

\section{THE INTERNET - A NEW MEDIUM IS DISCOVERED FOR SELF-PRESENTATION}

Familiarity with the PC and the internet is expected of people in professional life. The acquaintance with such skills promotes the use of the new media in the private domain where computers and the internet have become more and more common.

In 1996 only $4 \%$ of Austrians aged 14 and above had access to the internet from their home PCs. In the first quarter of $200454 \%$ of Austrians belonging to that age-group were able to access the internet from home (http://mediaresearch.orf.at). When the new medium internet made its appearance in private households private people were given the opportunity of an active-productive utilization of the new medium. ${ }^{1}$ This pervasion of computer technology in the domestic domain brought forth some amazing phenomena. Among these are personal homepages, which primarily serve the self-presentation of their authors.

\section{THEORETICAL REFLECTIONS ON SELF AND SELF-PRESENTATION}

Mead describes the development of self as a process located within social interaction (see Mead 1980a, 1980b, 1983, Blumer 1978). Individuals cannot exist severed from others; and the self (or identity) emerges from social processes. Therefore the self of the single individual is not given by birth, but unfolds little by little and is formed as a result of social experience. The process of developing one's self is seen as a process of socialisation. The basis for the development of self and consequently the socialisation according to Mead is the capability of man to shift perspectives. Man 
therefore is intellectually capable of making himself the object of contemplation from the perspective of others and so to anticipate courses of action and their consequences. The capability of assessing consequences of actions enables us to have a presentiment about the impression of our own person on others in the course of the socialisation process. Moreover this capability is the basis for the development of strategies by which we endeavour to create the desired impression within our social environment. For the very aspect of the self that corresponds with the internalised "generalized other" Mead introduces the term "me". Thus the "me" enables us to see ourselves in the way that we think others see us. It also includes expectations of which we assume that others want us to meet. On one hand the "me" provides the pattern for self-presentation in the sense of a fulfilment of expectations and at the same time functions as a sort of authoritative control in regard to the presumed outcome of our presentation, allowing us a glimpse on our own person from the outside ${ }^{2}$.

According to Goffman (2002) we are trying to make the ideal that we hold of our own person come true. We do so by playing various roles and by requesting the observers to take the impression that we are trying to evoke seriously. The audience is asked to believe that the character which is presented actually possesses the attributes that he seems to possess. With reference to the presented paper this means that the author of a homepage who presents himself as cool and successful asks the visitor of his page to take for granted that the presentation matches reality. Goffman maintains that the extent to which the actor himself believes in the genuineness of the role he plays differs greatly. The spectrum extends from actors who are completely taken in by the conception they have formed of themselves and are truly convinced that the impression they created is reality, to actors who do not think their own roles are true at all. So the single individual may be deceived by his own performance or regard it in a cynical way. The cynical actor does not necessarily act for his own personal gain. More often than not he deludes his audience for their own good. Goffman uses the example of a doctor who prescribes his patients placebos because they show such a heartfelt demand for them in this context. R.E. Park (1950, quoted by Goffman, 2002) maintains that everyone is always and everywhere more or less consciously playing a role and presenting the self he would like to be. That statement also applies to personal homepages that often seem to be the manifestation of desires and ambitions. The authors of the homepages we investigated, for instance present themselves together with a car (Ferrari) they would like to possess, or by photographs taken during a trip to a large city and in a comment utter their wish for a life in a major city.

In personal homepages content that is positively valued in society is used for self-presentation. This includes items such as family (spouses, kids), 
friends, place of residence, the own house, pets, hobbies - often hiking, biking, tennis or soccer - and also holiday trips or events such as the wedding of the author, birth of a child or a birthday party. This tendency of authors to foster an idealized impression on their audience by trying to personalize officially accepted values of society is also described by Goffman (2002).

Another aspect of self-presentation that can often be found in personal homepages and which Goffman mentions as well is systematic modesty. Goffman describes the example of second-hand dealers who try to evoke a favourable impression for themselves by conveying that second-hand articles are without value and those dealing in them are poor and pitiable. As we found out modesty in personal homepages mostly refers to the skill of the author as designer of his page. But what is the advantage of the author resulting from showing modesty? He possibly wants to tell the audience that designing the homepage in question was not a big affair and hardly challenged his knowledge of programming. But he could also be trying to tell the audience that it was not possible for him to show his real skills for various reasons - perhaps restrictions of the provider. In both cases his modesty suggests "I am able to do better than what you get to see here". Another possible explanation for this modesty presumably lies in the fact that the author actually does not consider his homepage fully perfect and he takes a critical stance towards the outcome of his work. Thus he avoids criticism by individuals who might produce a better version. Systematic use of modesty can also be seen as an effort to provoke positive entries in the guest-book of the homepage. In this case the function of the understatement may be seen as "fishing for compliments". In all three variants of explanation the reason for the marked modesty could be fear of negative criticism in a field that is of eminent importance to the author's self-esteem expertise on the PC. Negative criticism in a field that is essential for the selfesteem implies a massive threat and evokes anxiety. A possibility to ward off this anxiety and to avoid an impending criticism is to demonstrate modesty.

\section{QUESTIONS}

Our paper is based on a study which investigates the self-presentation on homepages on three levels:

On the first level we explore the content that was used for presenting oneself on homepages and we examine if certain "dos and don'ts" have been established in the choice of content as well as in the way of presentation. 
The second level does a reconstruction of the significance of content for the given material within the author's scope of meaning.

On the third level the study tries to find cultural explanations for the "self-representation on personal homepages" phenomenon.

\section{THE METHOD}

The methodical approach orientates by hermeneutics used in social studies (Leithäuser and Volmerg, 1988) and is supported by semiotic analysis (Eco 1972, Kritzmöller 2002) .

The material used in this analysis is a set of 60 homepages created by people for personal use and published by wide-spread Austrian providers. The selection of the homepages used was made at random.

The challenge of the study results from the non-uniform structure of the material analysed. Personal homepages are complex patterns of pictures, wording, and context as well as acoustic signals and animated pictures. Personal homepages do not follow any linear course but are connected in a multitude of ways through hyperlinks.

\section{ANALYSIS OF ONE HOMEPAGE ${ }^{3}$}

The following in-depth-analysis of a homepage should on one hand illustrate the method of working and on the other it should make clear what a homepage reveals about the author and the attitudes that he articulates.

\subsection{Description}

The author of the homepage is a 36-year old male. On February 1, 2004 the homepage consisted of the topics "Wedding", "Me \& My Kids", "The Woman in My Life"“, "The House", "Neighbour's Cats", "Santorin", "Domrep", "Photographs", "Links", "Cartoons", "Poems", "Old and New Guestbook", "Mail", and "Home" together with a link to the "Francesco Cardeloni Travesty-Homepage". By June 29, 2004 two new topics were added, namely "Past" and "Cats" and the link to the "Francesco Cardeloni Travesty" was removed. 


\subsection{Evaluation}

Self-presentation on personal homepages as a play between desire and reality - the homepage as a "magic" place for realizing desires

The author welcomes the visitor of his homepage by quoting the following poem by Yvonne Berlanga-Navarro:

"Future. Dream, whatever dream you have. Go, where you wish to go. $\mathrm{Be}$, who you desire to be. Dare what you have always wanted to dare. Because: Someone who continues to do what he always has done, will get what he has always got." (Original in German)

By placing the poem at the beginning of his homepage - at the most prominent point - the author makes the lines "Dream, whatever dream you have. Go, where you wish to go. Be, who you desire to be. Dare what you always have wanted to dare." the motto of the pages designed by him and opens a play of self-presentation between desire and reality.

According to Goffman (2002) the realisation of desires referring to one's own person is effected by playing roles. That is to say we more or less conscientiously play roles, with which we are trying to be in accordance with the respective ideal, and we are anxious to make our social environment believe in the created impression, to make them think it is real. If you consider the homepage as a new, additional possibility for self-presentation we may also assume that the play of self-presentation between desire and reality, which Goffman (2002) describes, is resumed in personal homepages. An important function of the homepage could therefore consist in its being a quasi magic place that makes desires placed in it come true. This hope that is tied to a personal homepage is expressed in the creation of subtopics such as "Happiness with a new partner". "Happiness in a new relationship" is explicitly made a topic in the rubrics "Wedding" (wedding announcement, wedding invitation, as well as a hundred photographs of the wedding celebration), "Dominican Republic" (a documentation of the first journey together), in the sub-topic "Me" of the topic "Me and My Kids" with statements such as "I have met a very special person. Everything I ever missed or dreamed of until today, has come true" and in the topic "The Woman in My Life" with statements such as "She (note: the new wife) simply has everything I want of a woman ...", "You are in every single breath", and "I love you". Indirectly you can also find the new happiness in the topics "The House" (the author and his new spouse had a pre-fabricated house built), "Neighbour's Cats" (the couple will be given a kitten by the neighbour), and "Santorin" (description of a holiday spent together). In seven out of eleven topics the author is explicitly or implicitly occupied with the topic "new happiness through new relationship". The wide extent to 
which the author's mind is occupied with this topic can be seen as a reference to the importance of the new relationship for the author.

But why does the author discuss this topic, which is probably important to him in such detail on his homepage? A possible explanation could be the presumed function of the homepages as a "magic" place for the fulfilment of wishes. The repeated placing of wishes on the homepage could be seen as a sort of magic charm, or incantation, which is to secure the realization of the manifested wishes. Following the motto "The more often something is recorded on the homepage and thus mentioned before witnesses as well as shown in pictures, the higher the chance of it becoming true."

Intimate information published on the homepage and primarily addressed to the partner such as "You are in every breath ...", and "I love you" have an embarrassing effect on the onlooker because they are not meant for him. What function might these public assertions bear? Possible explanations can be found in associations these intimate information has for the observer such as "the whole world has got to know how happy I am" so as "to make something public as evidence" or "to declare oneself for somebody in public". One aspect in the public declaration of love may be that of a demonstrative declaration for the new wife by proving that he stands by her - showing the declarations on the homepage to as many witnesses as possible. The public declarations of love could on the other hand also be seen as an attempt to clean out personal uncertainties with regard to the new partnership in order to gain certainty in respect to the new relationship. At the same time the public declarations of his love might be understood as precautionary measure in case the relationship fails; precautionary measure to the effect that if the relationship fails the author cannot be blamed for it because he evidently loves his new partner.

The author seems to go even further by creating a combined topic called "Me \& My Kids". He has another wish he would like to become reality: a link between his kids and himself. He creates this link by presenting himself and his children as belonging together designing his homepage this way and so making the dream "we belong together" come true. This combined topic stands out if compared to the others. There is no other topic on the homepage that is dedicated to more than one subject at the same time. There is a topic explicitly devoted to the new wife and also particular topics for subjects such as the new house or the neighbour's cats. The fact that the only topic that is devoted to more than one subject, one with information about the author and his children, brings forth associations in the sense of "(wanting to) demonstrate togetherness" or "(wanting to) display unity".

The homepage as medial platform for the realization of wishes is again evident in the explicit self-presentation when the author shows a picture of himself standing beside his favourite car, a Ferrari. He adds, "To my regret 
this car is not mine. Only borrowed for one day. Too bad! Was a wonderful experience all the same!"

\subsection{The explicit self-presentation - male, sportive, good- looking, successful}

The author presents himself on three photographs:

On the first picture he is leaning against the mudguard of a red Ferrari with one leg nonchalantly propped up on the tyre. He is dressed in cowboyboots, black trousers and a linden-green shirt, his hair is carefully styled. The scene reminds one of film shootings starring James Dean and certain associations emerge in one's mind such as "I am an attractive guy with a fast, expensive car", "I am handsome and I am good company", "women's hearts go out to me".

The second picture - a portrait - shows the author with a tanned face, dark sunglasses and a white $\mathrm{T}$-shirt. $\mathrm{He}$ is smiling with his arms folded across his chest. The man on the photograph signals to the onlooker the impression that he is satisfied with himself and aware of his attractiveness.

On the third picture the author appears tanned again, this time lying on the beach dressed in bathing shorts. By means of this photograph his sportive looks are shown extremely well.

According to Goffman's theory (2002), which implies that we are trying to realize the ideal image of ourselves in self-presentation, the selection of the presented photos indicates that physical attractiveness is of great importance to the author and that he is entirely satisfied with his looks.

The choice of the first photo, on which he presents himself with according to his own words - a borrowed red Ferrari shows that he wants to be seen as a man with typical male dreams like fast and expensive cars. This assumption is strengthened when considering his usage of the technical term "year of manufacture" from the automobile sector when stating his year of birth. Finally he lays emphasis on the fact that he works as an engineer for a well-known enterprise, which is still considered to be a purely male job, and shows he identifies himself with a stereotypical male image.

\subsection{Self-presentation as expression of success orientation}

Several hints - above all in the sub-topic "How It All Began - An Excursion Into Cedric's (note: synonym for the author) Past" of the topic "Me \& My Kids" make one believe that success takes up a central role in the author's system of values. He comments the photograph, which shows an approximately 5 year old boy sitting in the aircraft of a children's merry-go- 
round, with the words "He has always had high ambitions (though these were not always met)". The photograph dates from his childhood days but the comment was written by the author only recently. The statement can therefore be interpreted as an indication of the fact that the idea of having high ambitions still bears validity today. Furthermore he shows himself as a sportive boy on three out of eight photographs - tobogganing, skiing, and finally at a victory ceremony after a competition, where he apparently placed first, second or third. The comment that goes with the pictures reads, "Funnily enough I won most of the time" and with that he stresses the fact that he was good which again can be seen as a hint to the central importance of success in his way of thinking. The note "which wasn't too difficult with a bunch of Dutch who weren't trained for mountain ranges" puts his success in perspective. But it seems that he could not have this curtailment on his homepage because in the following sentence he states that his competitors had been taller than him which makes his success respectable again ("I was standing on a pedestal -damn it! How tall was this guy? ").

The significance of success for the author's self-image manifests itself in the explicit self-description where he mentions pool and bowling under "all that is fun". With "pool" and "bowling" - he once more names activities whose gist is to match one's own skills with the skills of competitors and therein shows his striving for still more success.

The high rating of success in his thinking is even visible on the holiday photographs in a weakened form. This can be considered a particularly strong indication for the significance of success in the life of the author because normally people on holiday can indulge in idling away their time in a socially legitimized way. The author shows that even in exceptional situations like that he finds it hard to free himself from success orientation. He comments a photograph in the section "Dominican Republic" as follows: "Here is a waterfall with about 18 steps. We climbed 7 of them "sweat". What an adventurous canyon climbing!" A second picture on which he apparently sluggishly lies on the slanting trunk of a palm tree he comments with "It wasn't that easy "grin*". Both statements show that it seems to be vital for the image he has of himself and his self-esteem that he is successful even when on holiday.

The pieces of information in the "Santorin" topic where he states what a successful holiday maker has to do in his opinion is a similar case, namely "... to find out quickly what one ought to see.", "A stroll along the rim of the crater is also a must", "At least once you should get your feet burned on the black beach of lava on Santorin", or "Finally I would like to say that it is a necessity to have seen Santorin."

The appearance of the topic "performance and success" in various sections of the homepage can be seen as a reference to the great importance 
of success-orientation in the ideal self-image of the author (see Goffman, 2002).

\subsection{Self-presentation as the striving for social appreciation}

As described above success seems to be of central importance to the author's self-concept which can also be seen as an expression of his striving for social appreciation. The strong need for appreciation by other people is also shown in his endeavour to combine the self-presentation as being successful with the message "I am just an ordinary person and one of you". This also becomes apparent from the set of photographs entitled "How it all began an excursion into Cedric's (note: synonym for the author) past". The four photographs, as described above, indicating a strong success orientation are followed by three pictures showing him as an ordinary boy and juvenile. On one photo he can be seen as a school-child playing in the sand on the beach. His comment reads as follows "Summer, sun, beach - realised very early as being pleasant!" On the second picture the author is depicted as a juvenile with a bottle of ketchup in hand and he writes ironically "My most important edible at that time! (Fortunately though there were quite voluminous sizes available ;-)". Finally he shows a photograph that was taken during everyday school-life and explains "Several arguments with a teacher prolonged the duration of my attendance at the technical high-school considerably ;-)" The joint statement of the three pictures could be as follows "I like what you like.", "I like to eat what you like to eat", "I had the same problems you had" and thus "I am one of you". It can also be seen as expression of the wish "I would like to be one of you" (see Goffman, 2002).

The endeavour to demonstrate togetherness is again shown in his listing of hobbies. The author mentions "my children, house and garden" as hobbies. These are domains in which he can be sure to meet with broad social approval (see Goffman, 2002).

Another clue to the presumptive endeavour to be seen as a sociable person can be found in listing billiards and bowling as hobbies. Both games are played together with other individuals. The information that the author likes to play both of these games can at the same time be understood as information that he often likes to spend his spare time in the company of others.

A further central aspect in the self-presentation seems to be the attempt to counteract the image of the dull and serious engineer. Thus the author emphasizes that his favourite spare time activity is "everything that is fun" and then mentions billiards and bowling. As hobbies are activities that are pursued out of one's own free will one can assume that these activities are 
pursued for fun. Why then does the author explicitly mention them as of being fun? One possible explanation might be the wish to state that he is by no means a dull engineer but that he has a sense of humour and wants to enjoy himself. The desire to be thought of as somebody who you can have fun with makes one assume that the author thinks it as socially desirable to be taken for a nonchalant and funny person and he wants to meet what is supposedly expected of him by designing his homepage.

The endeavour for the image of an easy-going person is made clear by the cartoons he placed on his page. Five of the six cartoons deal with the topic engineering in an ironic way. Three cartoons are devoted to the topic "MIR" one to the "Mars-landing" and one to "Sex in the internet". This ironic exposition of the engineer with the topic engineering makes him seem to be a representative of his group who is capable of laughing about jokes that are about topics important to him.

\subsubsection{Holidays, nature photographs, IKEA, and Ö3 - tokens of unconventionality within the social standards and a standardized escape from everyday life in the success oriented society}

The author dedicates two out of a total of eleven topics on his homepage to the presentation of holiday trips so that one can assume that holidays rank highly to him. The two holiday trips described are about a fortnight's vacation in the Dominican Republic and a fortnight's stay on the isle of Santorin. Currently the vacation in the Dominican Republic is illustrated using eight pictures, but a message states that this topic will be expanded in future. The pictures bring up associations of a "vacation in paradise". They show a deserted beach with palm trees and a waterfall - where no tourists can be seen, the author on the deserted beach, on the slanting trunk of a palm tree and the author standing on his own in the high waves.

In the "Santorin" section comments such as "You notice how you get calmer, more relaxed and the problems spinning around in your head fade away ..." indicate the assumed importance of the holiday trips as a sort of standardized frame for a temporary escape from the success orientated society.

In the "photographs" section the author presents the beauty of the landscape and nature. There are photographs that he shot himself as well as 12 photographs he downloaded from the internet. In addition to the pictures he offers explanatory information such as "my photograph of the comet", " $a$ view from the Koralpe in Carinthia", "The Koralpe again, higher up, some years later", "The waterfall on the Koralpe", "Have you ever seen Vienna in the morning?" The selection of photographs and the subtitles clearly 
show that the author perceives the beauty of the landscape and of nature and that he enjoys it. The following comment on a photograph that depicts a snow covered forest in the orange morning light shows that love of nature particularly well: "My absolute favourite" he writes. Photographs displaying the beauty of nature for him could be a further possibility of temporarily escaping the above mentioned success orientation that is so important to him; a possibility that involves only little time and financial expenditure.

The information that the journey to the Dominican Republic had been offered in the IKEA-family catalogue can bee seen as indication of a striving for non-conventionality within the social rules and standards: On the one hand the trip was not booked at a travel-office like people usually do; on the other hand the positioning of IKEA on the market expresses the enterprise's philosophy of being different to other enterprises. Well-known slogans of IKEA are for example "The furniture-shop from Sweden that is a bit different to others" or "The unusual furnishing-shop from Sweden". In its line of advertising IKEA carefully maintains the image of a young, uncomplicated enterprise by offering furniture and fixtures in modern design and of good quality at moderate prices and at the same time emphasizes its social commitment (improvement of working conditions and no toleration of child-labour with its suppliers) as well as pleading for the protection of the environment (co-operation with WWF).

The two photographs published in the "photographs" section were taken on a visit to the Ö3 (note: Austrian broadcasting station) studios and can again be understood as striving for non-conventionality within the social rules and standards. The author comments these pictures as follows: "Kudos to THAT Ö3-team! Continue your great work!!! (unfortunately they didn't manage to maintain that quality) Thank you L1SA!!" Similar to what IKEA stands for today, namely a non-conventional life-style, OO3, in the early years of the author (year of birth 1968), was the broadcasting station for the young generation. Ö3 broadcasted modern and consequently mostly English songs as well as ideas on socio-political topics which were considered popular and modern. Disappointment with the present style of the broadcasting station, proved by statements such as "Continue with your great work!!!! (unfortunately they didn't manage to maintain that quality) and "Unfortunately 03 wasn't able to think of anything new. What a pity ......", could be attributed to the fact that in the last years Ö3 has had to compete with several privately run stations of similar styles and therefore is not as outstanding as it used to be and has lost its uniqueness. Also, individuals of the author's age aren't the primary target group of the radio station and therefore do not feel as attracted to it as they did when they were younger.

The detailed presentation of the two holiday-trips, the nature photographs as well as the references to IKEA and Ö3 can be seen - in the sense of a self- 
presentation as realized ideal image of one's own person - as expression of the author's wish to be thought of as unconventional and to escape from success orientated everyday life without disappointing the alleged expectations of society.

\subsubsection{Traditional understanding of gender roles and passed-on rituals in the digital age as positioning of the private individual within the extended traditional frame}

In the "The Woman in My Life" section the author depicts an image of women that corresponds to the traditional view of the role a woman has to play in our society. By stating that his wife has everything that he wants of a woman and by listing up the appraised characteristic features he at the same time informs the onlooker of his ideal image of a woman. The author tells his audience that his ideal woman must have characteristics such as kindheartedness, tolerance, and beauty. She should always be good-humoured as well as be a good mother and a perfect entertainer. By wanting these characteristics he creates and validates an image of a woman that corresponds to the image of women within the traditional understanding of gender roles. The expressed desire for a partner who feels obliged to the traditional gender-role makes us assume that his own way of seeing himself and consequently the ideal image of himself corresponds to the traditional male gender-role. According to this appreciation of the gender-roles the tasks of a woman consist of supporting her husband, so that he can be successful in his professional life, and to take care of the education of the children. Furthermore the duties of a wife are to be attractive for her husband, to be a good companion, and to be a good hostess.

Moreover it is striking that the "Wedding" section is placed first on the table of contents of the homepage and that much attention was paid to the layout and design of this section. This is an indication of the great significance the wedding has had in the life of the author and it shows the high symbolic value of ceremonies for the author. An additional indication of the importance of the wedding can be seen in the supplementary subsection "photographs" (note: of the wedding) in which the author publishes a hundred photographs of the wedding-celebration. The wedding-ceremony at the registry office depicted on the photographs (the exchange of wedding rings, the signing of the wedding book), the celebration following the wedding (cutting of the wedding-cake together, barriers built-up in front of the entrance-door to the house of the couple), as well as the clothes of the bride (long, white wedding-dress, white pearls in her done-up hair, bridal bouquet primarily consisting of white roses), all speak for a choice of a traditional frame for the celebration. 
The design of the "Wedding" section - in regard to its contents reminds one of a classical conventional postal wedding announcement sent by parents of an engaged couple or by the engaged couple themselves. An old tradition has found its way into a new medium. This old custom of sending out wedding invitations still seems to be an apt form of organizing the celebration but there are some major differences between a web page and the conventional form of postal delivery: By placing the message on the homepage it is not exclusively addressed to involved individuals but reaches an unlimited number of people. Many of them have no personal relationship to the engaged couple. Designing a unique invitation quickly has become feasible by using computer programmes. The author of the homepage in question did the following: he placed an extract from the story "Do you know how much I love you" by Sam McBratney at the front of the page and uses the illustrations by Anita Jeram as a graphic frame of the section. The seeming uniqueness and personal note of this computer designed wedding announcement is, when looked at closely, a skilful combination of prefabricated stencils.

\subsection{Itinerary - self-presentation as staged expertise}

Currently the holidays in the Dominican Republic are illustrated by eight photographs. On five of them one can see either the author or his companion. This gives the compilation a very personal touch.

The selection of pictures the author chooses for the "Santorin" section is made using completely different criteria. In the whole compilation of 17 photographs not one can be found that shows the author or his partner. The photographs reveal - similar to professionally made travel-guides - the sights and natural beauty of the country. There is for example "a view of the Caldera", "a view of the crater-island of Nea Kameni", "the windmill at Oia", the "Sunset at Fira", the "Castell d'Aquila" or "an outlook on Perissa". The photos are commented and provide useful further information in the way that a travel guide would do this. In addition to that the author furnishes the reader with practical advice about good beaches, best time for travelling, climate, means of transport and good food and drink. He words the above-mentioned tips as follows: "In late September it is still rather hot but not unbearably so, you have got the beach all to yourself and even the water is still warm. For the duration of our stay we hired a scooter. Costs are tolerable and the island is so small that you can drive round it within one hour. Only the wind causes problems. It blows constantly, which makes travelling by scooter rather dangerous at times. I need not mention details about how people in Greece drive. There is not much to say about food and drink. If you stay away from tourist centres you will get good food." In his 
résumé the author once more expresses his wish to be seen as an expert and adviser with the words "Maybe my report will help someone (note: the visitor of the homepage) with the decision of where to go on his next holiday".

The design of the itinerary can be seen - in the sense of self-presentation as realized ideal (see Goffman, 2002) - as expression of the great importance for the author to be accepted as an expert.

\subsection{Presence on the Internet raises the significance of one's own life}

The author introduces his homepage with the words "These pages are totally absurd to some extent ...". Why does he take all the effort to design a web page whose contents he declares to be absurd? One answer to this question could be: Because it is important to him to be present on the internet with a personal homepage. One indication of the confirmation of this assumption is the choice of content for his homepage: The author expresses wishes, introduces the people important to him (himself; children, his new partner) and shows the things (house) and events (wedding, holidays) that are of importance to him. All this produces the impression that the author, by showing on his page the people, objects and events that are important to him, wants to bestow even more importance upon them. It seems that the author wants to transpose the wide-spread opinion that "all important things are in the newspaper" on to his homepage, believing that anything that goes public on a homepage gets more weight due to its publication.

\section{CONCLUSION}

Summing up one can say that the author uses the homepage as an additional possibility of self-presentation. By doing so the homepage becomes a quasi "magic place", that could contribute to the realization of wishes and desires. Regarding this he uses two strategies: On the one hand he tries to make his wishes come true by constantly repeating them in front of witnesses; on the other hand he directly makes his wishes come true through creative transformation on his homepage.

Furthermore the author communicates his self-image and expresses the norms and values that he thinks are important and valid: success, traditional gender roles, non-conventionality within social rules and standards. These consequently show his view of the world and at the same time the author transports important aspects of the ideal image of himself (see Goffman, 
2002, Mead, 1980a). Moreover he shows how high social appreciation ranks in his thinking.

Using the selection of content presented on the homepage he shows that people, objects and events that are important to him find their place on his homepage, and therefore he wants these to obtain additional importance.

The presented homepage is a typical example of a personal homepage. The homepages analysed by us do differ by various criteria, but the elements and dimensions that we found in the homepage presented in detail can also be identified in the other homepages that we looked into.

The analysis of all the personal homepages examined by us until now taken as a background, several generalising conclusions can be drawn from the presented in-depth analysis of Cedric's homepage:.

\subsubsection{Concerning the choice of contents}

The opportunity of designing personal homepages for self-presentation has become something accepted. Some homepages are organized very elaborately (for example 100 photographs of the wedding, lexical listing of private indoor plants and outdoor plants, illustration of private hiking- and biking-tours that are similar to official travel guides).

Certain topics have established themselves when creating personal homepages. Among them are self-descriptions, childhood memories and memories of one's youth, people close to the author (partner, children, parents, friends), pets (primarily cats and dogs), houses and (not as common) flats, place of residence, the car and/or motorbike, holiday trips, free time activities (above all sports and creative activities) and information on important events in the life of the author (wedding, birth of a child, birthdays).

Besides being used for self-presentation in the narrow sense personal homepages are also used as medium for the publication of works in the scientific field written by the author of the homepage such as project papers written in the final school years, diploma thesis, thesis, but also self created art such as poems and guides. The personal homepage enables the author to publish his own work independently of publishers and so enables him to keep his autonomy.

\subsubsection{Concerning the immanent significance of contents within the author's scope of meaning}

Very often wishes and desires are voiced on personal homepages. The creative design of the homepage makes it possible to accomplish, at least partly, one's own wishes (e.g. photograph with one's favourite car). By 
creating the homepage (above all in sections named "fun" or similar) personal fantasies are made public.

Objects and events are presented on the homepage that have (mostly positively) impressed the author. Also occurrences that fascinate authors are presented on homepages (e.g. a young author living in a small town reveals his fascination for high buildings and tells how much a trip to a big city had impressed him).

The wide-spread installation of guest books can be seen as expression of a hope for a positive feed-back and thus as a strengthening of self-esteem. Counters carry a similar function. The higher the number of visitors the more the self-esteem is given. In the self-presentation the author reveals the norms, values and attitudes that are important to him (e.g. the importance of success, traditional view of women's role in society).

\subsubsection{Concerning socio-cultural aspects}

Personal homepages can be seen as an indicator for the disappearance of the dividing line between private and public life in society (see Steinhardt 1999).

Personal homepages also indicate a high rating of the importance of a media presence in society. Prestige in contemporary society seems to be linked with media presence. Presence in the internet through personal homepages can therefore serve as an attestation of one's personal importance. In modern society access to the media and thus the possibility for spreading information in public was increasingly restricted to a few people only (Habermas 1990). Because of their ease of access homepages can now serve as a platform of speech for many. For quite a number of people this raises the question what the content of these public statements is. As described above very often one's own person and one's own life are the subject of a personal homepage. The act of articulation seems to be more important than the actual information (see Steinhardt 2002). But if so many people articulate themselves in the internet: who is there left to read the enormous number of publications that flood the internet? Does this development lead to white noise in which the act of communication is drowned out? If this is the case, G. Franck would, in the end, be right with his metaphor of the beer pub where everyone talks at the top of their voice and every single person has to shout in order to be heard.

\section{NOTES}

${ }^{1}$ The interrelationship and the interactions between technical artefacts and people, who use them, can be conceived as socio-technical figurations. This 
term refers to N. Elias' concept of figuration (Elias 1970) and stresses the network of connections and interdependences between technology and social life.

${ }^{2}$ The "I", however, is -according to Mead (1980a) - the moment of spontaneity and creativity against the expectations from outside.

${ }^{3}$ The analysis of this homepage is an extract from a forthcoming diplomathesis by $\mathrm{H}$. Glatzmeier

\section{REFERENCES}

Beck, U. (2001): Risikogesellschaft: Auf dem Weg in eine andere Moderne. (16. Auflage). Frankfurt am Main (Suhrkamp)

Blumer H. (1978): Der methodologische Standpunkt des symbolischen Interaktionismus. In: Arbeitsgruppe Bielefelder Soziologen (eds.): Alltagswissen, Interaktion und gesellschaftliche Wirklichkeit. Vol. 1.Reinbek (Rowohlt), p. 80-146.

Eco U. (1972): Einführung in die Semiotik. München (Fink)

Elias N. (1970): What is Sociology? London (Hutchinson)

Franck, G. (1998): Ökonomie der Aufmerksamkeit. München (Hanser)

Goffman, E. (2002): Wir alle spielen Theater. Die Selbstdarstellung im Alltag. 10. Auflage. München ( Piper)

Haug W.F. (1971): Kritik der Warenästhetik. Frankfurt am Main: Suhrkamp.

Habermas J. (1990): Strukturwandel der Öffentlichkeit. Frankfurt/Main (Suhrkamp)

Horkheimer, M. \& Adorno, T.W. (1996): Dialektik der Aufklärung. Philosophische Fragmente. (3. Auflage). Frankfurt am Main (Suhrkamp)

Kritzmöller M. (2002): Positionierung im Lebensstil-Labyrinth. Frankfurt (Peter Lang)

Leithauser, T. \& Volmerg, B. (1988): Psychoanalyse in der Sozialforschung. Eine Einfuhrung am Beispiel einer Sozialpsychologie der Arbeit. Opladen (Westdeutscher Verlag)

Mead G.H. (1980a): Geist, Identitatt und Gesellschaft. Frankfurt (Suhrkamp)

Mead G.H. (1980b): Gesammelte Aufsätze .Vol. 1. Frankfurt (Suhrkamp)

Mead G.H. (1983): Gesammelte Aufsätze. Vol. 2. Frankfurt (Suhrkamp)

Steinhardt G. (1999):Auf dem Weg zur kaleidoskopischen Wahrnehmung. Überlegungen zur Subjekt-Konstitution und Welt-Erfahrung im Zeitalter der neuen Informations- und Kommunikationstechnologien. Psychosozial 22 (1999) 1, p. 81-98.

Steinhardt G. (2002): Das Subjekt im Netz. Identităt und Kommunikation im Zeitalter des Internet. psychosozial 25 (2002) 3, 27-46.

\section{INTERNET}

http://mediaresearch.orf.at 